\title{
Alfalfa hay crop loss due to mule deer depredation
}

\author{
DENNIS D. AUSTIN, PHILIP J. URNESS, AND DARIN DUERSCH
}

\begin{abstract}
Authors are research biologist, professor (now deceased), and wildlife technician, Rangeland Resources Department, Utah Stafe University, Logan, Utah $84322-5230$.
\end{abstract}

\begin{abstract}
To define alfalfa crop loss from depredating mule deer, the spotlight count and paired plot techniques were applied in 12 fields located throughout Utah. Protected and grazed plots were used to determine alfalfa loss. A significant relationship between deer-nights of grazing and alfalfa loss was determined. Based on our studies, we recommend using $2.4 \mathrm{~kg} /$ deer-night for mule deer depredation of alfalfa using the spotlight count assessment technique. Nutritional quality of alfalfa was not different between grazed and protected plots.
\end{abstract}

Key Words: Utah, deer diets, big game damage, crop loss evaluation

Wildlife managers must be able to accurately estimate crop losses from depredating big game to address the conflicts between ranchers and wildlife agencies. Although state legislatures determine the legal levels of state versus landowner responsibilities for wildlife depredation on private lands, state wildlife agencies are required to work with landowners and provide suitable alternatives or solutions to problems related to depredating big game.

An economically important and widespread depredation conflict occurs between big game and field grown alfalfa (Medicago sativa $\mathrm{L}$.). Supplemental feeding of alfalfa hay in winter is critical to the success of many ranching operations and reduction of winter feed due to depredation can cause significant economic loss. Depredation begins with the onset of alfalfa growth in early spring, peaks just before native vegetation becomes available, and declines rapidly as grasses, followed by forbs, become available in adjacent rangelands and forests. Summer depredation (mid May-August) is minor compared to spring use, but as native vegetation matures and desiccates in late summer, increasing use is usually observed on irrigated alfalfa fields adjacent to rangelands (Bartmann 1974, Austin and Umess 1993).

In our initial study (Austin and Urness 1993) we defined counting methods and our results yielded a first approximation for field-growing, alfalfa crop loss from mule deer (Odocoileus hemionus hemionus Rafinesque) depredation. The major advantage of using nighttime counts versus paired plots is the great reduction in time and materials needed (Austin and Urness 1993).

This report is a contribution of the Utah State Division of Wildlife Resources, Federal Aid Project W-105-R. The authors appreciate the many employees of the Utah Division of Wildlife Resources who assisted in this study.

Manuscript accepted 3 Feb. 1997.
However, clearly the value representing alfalfa loss/counted deer is critical and must be derived from many replications over a larger geographic area than our initial 6 replications in northern Utah. Therefore, our major objective in this study was to define this value for widespread applicability.

\section{Methods}

During early spring 1993, 12 privately-owned, irrigated alfalfa fields were selected for study. Fields were located throughout Utah from Rich County in the north to Kane County in the south. All fields had a history of heavy depredation use by mule deer. Areas of all fields were measured. In each field 20 pairs of protected and grazed $1-\mathrm{m}^{2}$ circular plots were established. Location of plots within each field was determined from an equal-spaced grid, using a randomized block design. Protected plots, selected by coin toss, were fenced with $1.2 \mathrm{~m}$ high, $15 \mathrm{~cm}$ mesh wire secured with 2 steel posts. Plots were established before spring growth was available or immediately following removal of the first or second alfalfa crop. On 10 fields, data from both the first and second hay crops were collected for depredation crop loss analyses. On these fields only 2 crops were harvested. On 1 field (trial 24), because deer had completely migrated from the area, data from only the first crop were collected. On 1 field (trials 5 , 6,7 ) data from 3 harvested alfalfa crops were collected. Also on 1 field (trial 7), a few Rocky Mountain elk (Cervus canadensis nelsoni Bailey) were counted and those numbers converted to deer-nights using a deer to elk weight ratio of 4:1 (Anderson et al. 1974, Thorne 1976).

Within a wcck of commercial harvest, plots were clipped to ground level and alfalfa was placed in marked paper sacks. In trials 11 and 22 the number of paired plots was reduced to 6 and 15 , respectively, due to unintentional commercial harvest. Stubbleheight plots (5/trial) were randomly located in fields and also clipped to obtain weights of alfalfa left in fields after harvest. Time constraints limited the number of stubble plots clipped. The mean stubble-height weights for each trial were used as tare weights and subtracted from clipped plots to obtain net alfalfa harvested but had no effect on production differences between paired plots. All alfalfa samples were allowed to air dry to room temperature and weighed to $0.01 \mathrm{~g}$.

Because variability of depredation use of alfalfa was extreme, each crop on each field was considered a separate experiment. In total, data were collected from a sample size of 24 trials. T-tests for paired comparisons (Sokal and Rohlf 1981) were used to determine production differences in alfalfa production between grazed and protected plots. 
Alfalfa samples for comparing protected and grazed plots for nutritional parameters were also collected. To reduce costs and the number of nutritional samples needed for analyses, alfalfa samples were collected and combined from consecutively numbered plots in groups of 4 . Only the samples from fields where alfalfa production was significantly reduced were analyzed. Samples were air dried and subjected to near infrared reflectance (NIR) spectroscopy at the Utah State University Soils, Plant and Water Analysis Laboratory. Single classification analyses of variance (Sokal and Rohlf 1981) were used to determine differences between grazed and protected plots for individual nutritional parameters. Analyses included protein, phosphorus, calcium, neutral detergent fiber, digestible dry matter, and metabolizable energy.

To determine the number of deer-nights of depredation by mule deer, weekly counts were made 1-2 hours after sunset using spotlights, binoculars, and horn. Local wildlife biologists and project personnel conducted counts, but not duirng inclement weather. Due to weather and personnel time conflicts, the number of days was not consistent between counts, and therefore the midpoints between counts were used to determine the number of nights represented by each count. The number of deer-nights for each trial was calculated by multiplying the number of deer counted by the number of nights the count represented.

Differences between grazed and protected plots and areas of fields were used to calculate alfalfa crop loss as $\mathrm{kg} / \mathrm{ha}$. Deernights of depredation were also calculated as deer-nights/ha. Data from deer-nights/ha and alfalfa loss $\mathrm{kg} / \mathrm{ha}$ were used to calculate a linear regression equation and correlation coefficient.

\section{Results and Discussion}

Reduction in alfalfa production ranged from $0-40 \%$ and significant losses from depredating mule deer occurred in 8 of 24 trials (Table 1). Deer-nights/ha ranged from 0-959. In trials where deer significantly decreased alfalfa production, total losses ranged from 1.3-4.2 ( $\overline{\mathrm{x}}=2.6, \mathrm{SE}=0.9, \mathrm{n}=8) \mathrm{kg} /$ deer-night of air-dry weight. Where deer use of fields exceeded 50 deer-nights/ha, alfalfa loss ranged from $0.4-4.2(\bar{x}=2.2, S E=1.1, n=13)$ $\mathrm{kg}$ /deer-night. Combined data from all 24 trials, obtained by summing all alfalfa production figures from grazed and protected plots, and summing all deer-nights/ha, yielded a mean alfalfa loss of $2.4 \mathrm{~kg} /$ deer-night. The relationship between deer-nights $/ \mathrm{ha}(\mathrm{X})$ and alfalfa losses in $\mathrm{kg} / \mathrm{ha}(\mathrm{Y})$ yielded the linear equation $\mathrm{Y}=$ $2.46 X-11$. The coefficient of determination was $r^{2}=0.89(P=$ 0.001 ), indicating deer utilization of alfalfa accounted for most of the variation in alfalfa production between paired plots.

No significant differences were found between grazed and protected plots for any of the nutritional parameters measured.

Grazing of field-growing alfalfa by deer can reduce yield significantly. Significant $(P<0.05)$ losses occurred when the alfalfa crop was reduced about 15 and $20 \%$, by depredating white-tailed deer (Odocoileus virginiana Zimmerman) (Palmer et al. 1982, Mullen and Rongstad 1979) and 18\% for mule deer (Austin and Urness 1993). In this study significant losses were detected when utilization of alfalfa exceeded $14 \%$ and were not detected at utilization levels below $10 \%$.

Table 1. Consumption of alfalfa by mule deer determined from $1.0 \mathrm{~m}^{2}$ paired plots and nighttime counts in Utah, 1993.

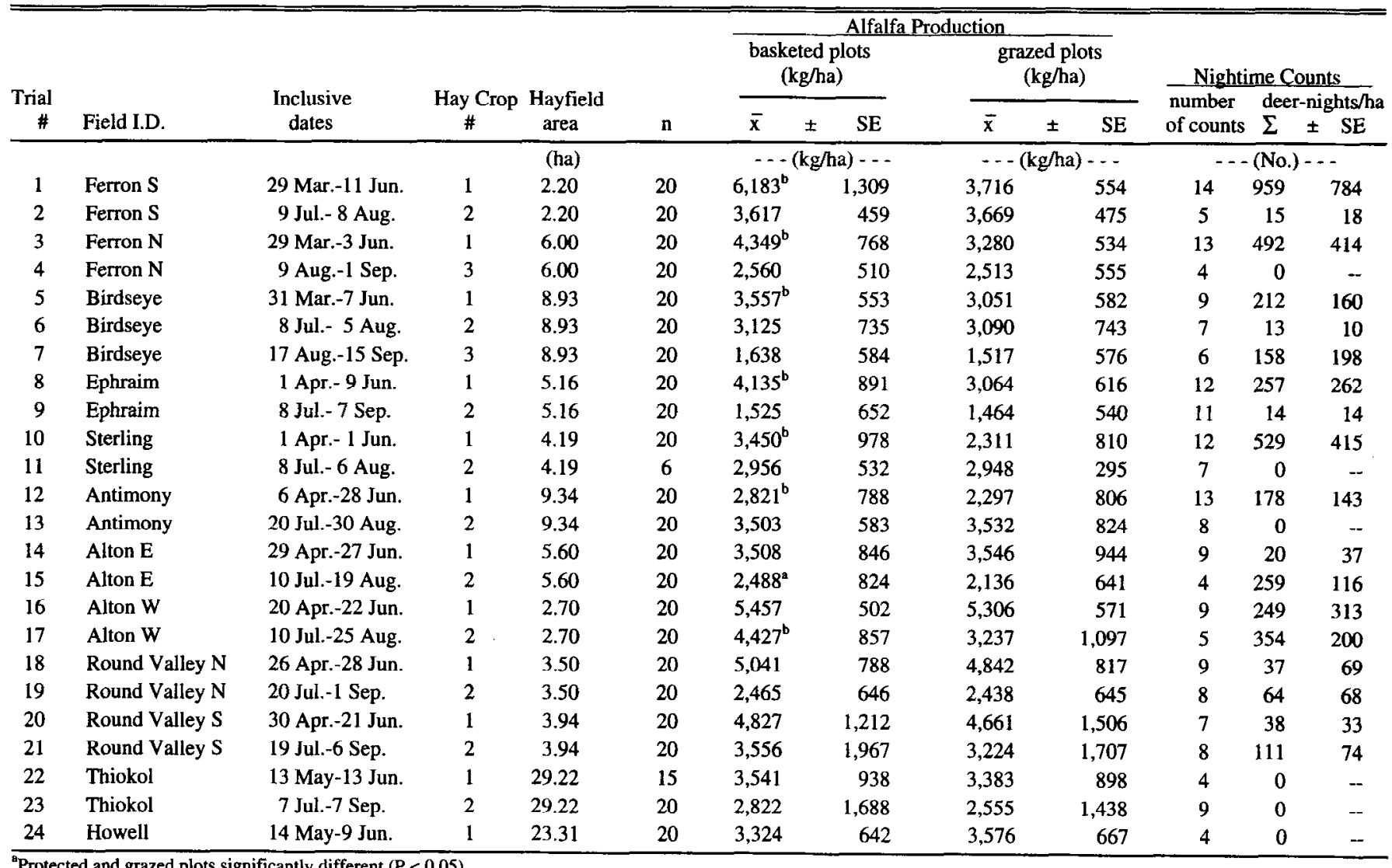

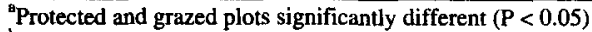

'Protected and grazed plots significantly different $(P<0.01)$ 
Reduction in alfalfa yield due to deer depredation translates directly into potential economic loss. For example, an average 10 ha alfalfa field might produce $\mathbf{4 0}$ metric tons of first crop alfalfa. At $14 \%$ crop loss (5.6 metric tons), the economic loss would be $\$ 280.00$ based on a stump crop value of $\$ 50.00 /$ metric ton. Using $2.4 \mathrm{~kg} /$ deer-night, 2,333 accumulated deer-nights would be needed. Also using a 60-day, first crop growing cycle, an average nighttime count of about 39 deer would equate to this loss. (Example data suggested by Utah Cache County extension office).

Forage consumption of fresh alfalfa by mule deer was reported as 1.1 to $1.5 \mathrm{~kg} / 100 \mathrm{~kg}$ body weight varying by alternative available feed (Austin and Umess 1987), and about $1.1 \mathrm{~kg} / 100 \mathrm{~kg}$ body weight using fecal material to estimate percent alfalfa contribution to the diet (Tebaldi and Anderson 1982). Estimates of alfalfa consumption/deer-night of grazing in fields were 0.8-1.5 $\mathrm{kg}$ in Utah (Austin and Urness 1992) and $1.4 \mathrm{~kg}$ in Wisconsin for white-tailed deer (Mullen and Rongstad 1979). However, the above studies were based only on alfalfa consumption and did not consider trampling and bedding, impacts on alfalfa growth potential, and spotlight counts (Bartmann 1974), which inherently fail to count all deer using fields. Our previous study (Austin and Urness 1993) included these additional potential alfalfa losses and yielded similar results of $2.2 \mathrm{~kg} /$ deer-night. Therefore, using nighttime spotlight counts, our results indicate alfalfa loss from mule deer depredation may be estimated between 2.2 and 2.6 $\mathrm{kg} /$ deer-night.

\section{Literature Cited}

Auderson, A.E., D.E. Medin, and D.C. Bowden. 1974. Growth and morphometry of the carcass, selected bones, organs, and glands of mule deer. Wildl. Monogr. No. 39.

Austin, D.D. and P.J. Urness. 1987. Consumption of fresh alfalfa hay by mule deer and elk. Great Basin Nat. 47:100-102.

Austin, D.D. and P.J. Urness. 1992. Guidelines for appraising crop losses due to depredating big game. Utah. Div. Wildl. Res. Publ. No. 92-4.

Austin, D.D. and P.J. Urness. 1993. Evaluating production losses from mule deer depredation in alfalfa fields. Wildl. Soc. Bull. 21:397-401.

Bartmann, R.M. 1974. Guidelines for estimating deer numbers in connection with damage claims to growing crops. Colo. Div. Wildl. Game Inf. Leafl. 97.

Mullen, C.A. and O.J. Rongstad. 1979. Evaluation of deer damage to hay in southern Wisconsin. P. 143-153. In: J.R. Beck (ed)., Vertebrate pest control and management materials. Amer. Soc. for Testing and Materials, Spec. Tech. Publ. 680. Philadelphia, Penn.

Palmer, W.L., G.M. Kelly, and J.L. George. 1982. Alfalfa losses to white-tailed deer. Wildl. Soc. Bull. 10:259-261.

Sokal, R.R. and F.J. Rohlf. 1981. Biometry, 2nd Ed. W.H. Freeman and Company, N.Y.

Tebaldi, A. and C.C. Anderson. 1982. Effects of deer use on winter wheat and alfalfa production. Wyo. Game and Fish Dept. Job Final Rep. FW-3-R-26.

Thorne, T. 1976. Elk weigh in. Wyoming Wildl. 40:24-27.

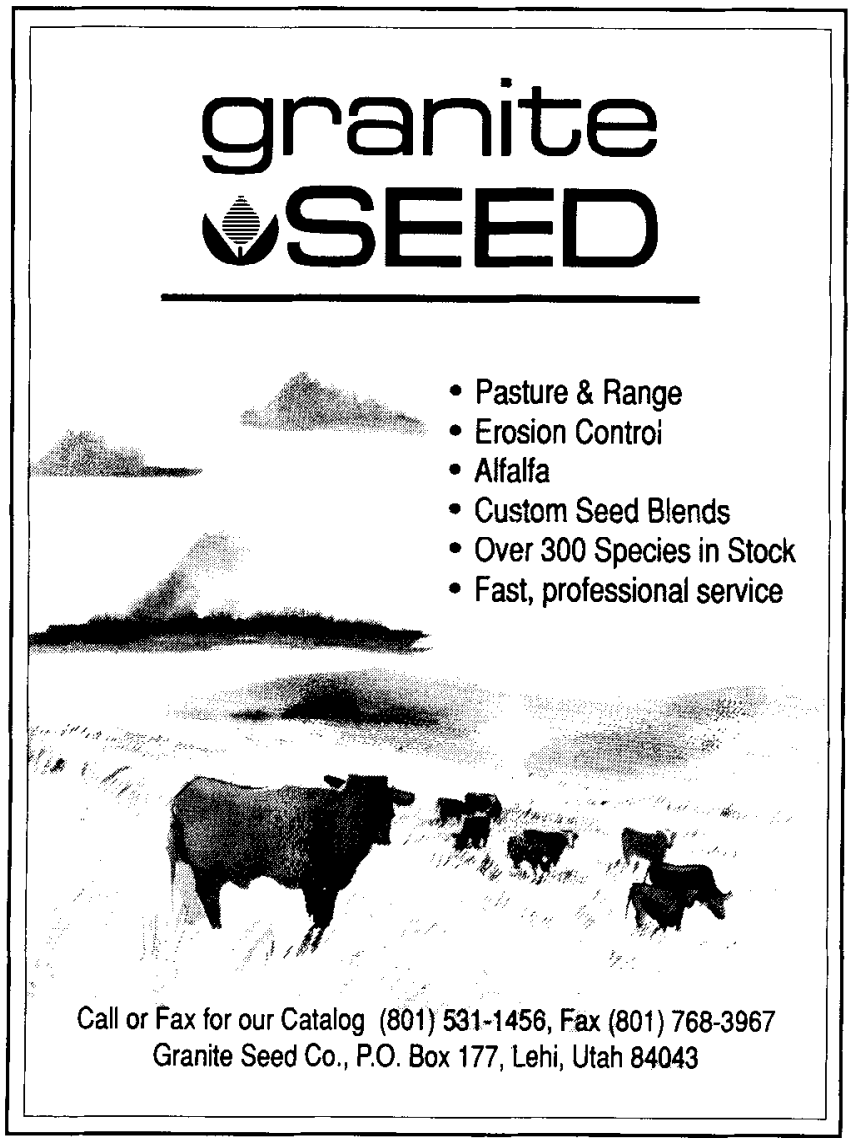

